\title{
Development of a Core Curriculum Framework in Cariology for U.S. Dental Schools
}

\author{
Margherita Fontana, DDS, PhD; Sandra Guzmán-Armstrong, DDS, MS; Andrew B. \\ Schenkel, DMD, MS; Kennneth L. Allen, DDS, MBA; John Featherstone, PhD; Susie \\ Goolsby, DDS, MSHA; Preetha Kanjirath, BDS, MDS, MS; Justine Kolker, DDS, PhD; \\ Stefania Martignon, DDS, PhD; Nigel Pitts, BDS, PhD, FDS (RCS Eng), FDS (RCS Edin), \\ FFGDP (UK), FFPH, FRSE; Andreas Schulte, DDS, PhD; Rebecca L. Slayton, DDS, PhD; \\ Douglas Young, DDS, EdD, MBA, MS; Mark Wolff, DDS, PhD
}

\begin{abstract}
Maintenance of health and preservation of tooth structure through risk-based prevention and patient-centered, evidencebased disease management, reassessed at regular intervals over time, are the cornerstones of present-day caries management. Yet management of caries based on risk assessment that goes beyond restorative care has not had a strong place in curriculum development and competency assessment in U.S. dental schools. The aim of this study was to develop a competency-based core cariology curriculum framework for use in U.S. dental schools. The Section on Cariology of the American Dental Education Association (ADEA) organized a one-day consensus workshop, followed by a meeting program, to adapt the European Core Cariology Curriculum to the needs of U.S. dental education. Participants in the workshop were 73 faculty members from 35 U.S., three Canadian, and four international dental schools. Representatives from all 65 U.S. dental schools were then invited to review and provide feedback on a draft document. A recommended competency statement on caries management was also developed: "Upon graduation, a dentist must be competent in evidence-based detection, diagnosis, risk assessment, prevention, and nonsurgical and surgical management of dental caries, both at the individual and community levels, and be able to reassess the outcomes of interventions over time." This competency statement supports a curriculum framework built around five domains: 1) knowledge base; 2) risk assessment, diagnosis, and synthesis; 3) treatment decision making: preventive strategies and nonsurgical management; 4) treatment decision making: surgical therapy; and 5) evidence-based cariology in clinical and public health practice. Each domain includes objectives and learning outcomes.
\end{abstract}

Dr. Fontana is Professor, School of Dentistry, University of Michigan; Dr. Guzmán-Armstrong is Clinical Associate Professor, College of Dentistry and Dental Clinics, University of Iowa; Dr. Schenkel is Clinical Associate Professor, College of Dentistry, New York University; Dr. Allen is Clinical Associate Professor, College of Dentistry, New York University; Dr. Featherstone is Professor and Dean, School of Dentistry, University of California, San Francisco; Dr. Goolsby is Assistant Professor, School of Dentistry, Virginia Commonwealth University; Dr. Kanjirath is Assistant Dean, College of Dentistry, Midwestern University-Illinois; Dr. Kolker is Clinical Associate Professor, College of Dentistry and Dental Clinics, University of Iowa; Dr. Martignon is Professor, Universidad El Bosque, Bogotá, Colombia and Senior Lecturer, King's College, London; Dr. Pitts is Professor, King's College, London; Dr. Schulte is Professor, Department for Special Care Dentistry, Dental School, University of Witten/Herdecke, Witten, Germany; Dr. Slayton is Professor and Chair, Center for Pediatric Dentistry, University of Washington; Dr. Young is Professor, Arthur A. Dugoni School of Dentistry, University of the Pacific; and Dr. Wolff is Professor, College of Dentistry, New York University. Direct correspondence to Dr. Margherita Fontana, School of Dentistry, University of Michigan, 1011 N. University Ave., Room 2393, Ann Arbor, MI 48109-1078; 734-647-1225; mfontan@umich.edu.

Keywords: dental education, dental caries, cariology, caries management, curriculum, competency

Submitted for publication 9/25/15; accepted 12/1/15

$\mathrm{D}$ ental caries is a multifactorial disease process that results in the localized destruction of susceptible dental hard tissue by acidic byproducts resulting from bacterial fermentation of dietary carbohydrates. If allowed to progress, the disease will result initially in the development of non-cavitated caries lesions, which if left untreated might further progress to cavitation. ${ }^{1,2}$ Although dental caries is a largely preventable disease, untreated cavitated caries lesions in permanent teeth are still the most prevalent health condition in the world and in primary teeth are the tenth most prevalent condition, ${ }^{3}$ with the possibility of many dental, medical, social, and quality of life sequelae. ${ }^{4}$ 
Caries management focused primarily on tooth restoration has proven ineffective at controlling the risk of future disease. ${ }^{5}$ In fact, maintenance of health and preservation of tooth structure through risk-based prevention and patient-centered, evidence-based disease management, reassessed at regular intervals over time, have been recognized as cornerstones of modern caries management. ${ }^{6-10}$ Yet caries risk assessment and management that go beyond restorative care have not always had a strong and organized place in curriculum development and competency assessment in U.S. dental schools, even though improvements have been occurring over the last decades, ${ }^{9,11}$ with the development of cariology curriculum programs, ${ }^{12}$ implementation of risk assessment protocols, ${ }^{12}$ and standardization in cariology nomenclature for use in U.S. dental education. ${ }^{1,8}$

The current Commission on Dental Accreditation (CODA) Accreditation Standards for Dental Education Programs fail to reflect the importance of, and fail to mandate, competence in diagnosis, risk assessment, and management of dental caries as they do for multiple oral diseases such as periodontal, oral-mucosal, pulpal, and others (e.g., CODA standard 2-23 currently does not mention caries). ${ }^{13}$ Furthermore, there is a great discord between the recognized need for risk-based caries management and prevention and the infrequent application of these concepts in clinical practice. ${ }^{14}$ Although many reasons may explain this lack of implementation, ${ }^{8}$ there is no doubt that dental education can help bridge the gap between research and practice to accelerate adoption of evidence-based strategies for the management of dental caries. ${ }^{11}$ Survey data regarding cariology curricula being taught in dental schools around the world (e.g., in Europe, ${ }^{15}$ Colombia, ${ }^{16}$ Brazil, ${ }^{17}$ and the U.S. ${ }^{18}$ ) have been used as a starting point for building a curriculum framework for cariology education based on best available evidence to provide a uniform but flexible platform for what should be included and assessed.

In 2011, a Core Curriculum for Cariology (CCC) for dental schools in Europe was developed under direction of the European Organization for Caries Research (ORCA) and the Association of Dental Education in Europe (ADEE).$^{18}$ The European curriculum is divided into five domains or themes, defined as a "broad, critical category of activity for the general dentist" in the American Dental Education Association (ADEA) Competencies for the New General Dentist. ${ }^{19}$ Those domains are as follows: the knowledge base; ${ }^{20}$ risk assessment, diagnosis, and synthesis; ${ }^{21}$ treatment decision making: preventive strategies and nonsurgical management; ${ }^{22}$ treatment decision making: surgical therapy; ${ }^{23}$ and evidencebased cariology in clinical and public health practice. ${ }^{24}$ Following publication of that core curriculum, efforts have been developing around the world to implement it in various educational systems. For example, in 2014, the Colombian chapter of the Global Alliance for a Cavity-Free Future (ACFF) decided to modify and rework the European CCC to facilitate its adoption by all Colombian dental schools. ${ }^{25}$

The aim of this study was to develop a competency-based core cariology curriculum framework for use in U.S. dental schools. This article reports on the process used to develop the framework on the basis of national and international evidence and consensus on current and future educational needs in the field of cariology. As dental erosion and tooth wear defects are normally taught in the U.S. along with cariology content ${ }^{26}$ these were also included in this framework, as in Europe.

\section{Methods}

The University of Michigan Institutional Review Board considered this activity to be "not regulated as human subjects research." The 2015 ADEA Section on Cariology officers (Drs. Margherita Fontana, Sandra Guzmán-Armstrong, and Andrew Schenkel), who became the Curriculum Planning Team (CPT), planned a consensus working agenda with the purpose of initiating discussion on current and future educational needs in the field of cariology in the U.S. and ultimately developing a U.S. curriculum framework. Three phases were planned and carried out as part of this process.

\section{Phase I: Preliminary Discussions and Information Dissemination}

The purpose of this phase was to initiate preliminary discussions during the 2014 Eastern and 2015 Central CAMBRA (Caries Management by Risk Assessment) coalitions' annual meetings. The CAMBRA coalitions involve groups of schools and other interested parties that meet regionally on an annual basis to discuss topics related to cariology and dental education and practice. The Central CAMBRA coalition meets as part of the Academy of Operative Dentistry Annual Meeting, and the Eastern CAMBRA coalition meets as part of the re- 
gional Consortium of Operative Dentistry Educators (CODE) meeting on the East coast.

During the November 2014 Eastern CAMBRA meeting and the February 2015 Central CAMBRA meeting, the proposed planned agenda for developing a U.S. CCC was presented as an opportunity for all attendees to participate in providing feedback regarding the planned process. In addition, the goals and main objectives of the five domains of the European $\mathrm{CCC}$ were reviewed, and feedback was received regarding the most beneficial format in which to present this information to U.S. dental educators for future discussion, as well as identifying areas to be considered for inclusion.

\section{Phase II: Workshop to Develop Curriculum Framework}

In preparation for the second phase of this initiative, the CPT reached out at the end of 2014 (with a reminder sent in early 2015) to all U.S. dental school deans $(\mathrm{N}=65)$ through the ADEA deans' listserv to invite at least one representative from each U.S. dental school currently involved in teaching cariology/ restorative sciences to attend a full-day workshop to develop a U.S. curriculum framework. This format was based on the process successfully followed during development of the European and Colombian core cariology curricula. ${ }^{18,25}$ To aid in planning this workshop, the assistance of the organizers of the European and Colombian efforts was secured (Drs. Nigel Pitts, Andreas Schulte, and Stefania Martignon).

The workshop was also announced on the listservs of the ADEA Sections on Cariology, Operative Dentistry, Community and Preventive Dentistry, and Academic Affairs, as well as through the Central, Eastern, and Western CAMBRA coalition networks. The workshop was planned to immediately precede the 2015 ADEA Annual Meeting to facilitate travel and encourage attendance of dental educators. The European CCC publication ${ }^{18}$ and editable tables in Word, developed to mimic the ones used in Colombia, ${ }^{25}$ were distributed two weeks prior to the meeting to all registered attendees. There was one table for each domain. ${ }^{18}$

For each curricular domain, the European CCC includes "major and supporting competencies," following definitions provided by ADEE. The major competencies were defined as "the ability of a dentist on graduation to provide a particular, but complex, service or task. Its complexity suggests that multiple and more specific abilities (supporting competencies) are required to support the major competency." 18 The Colombian CCC changed the word "competency" to "main and specific learning objectives" to align with the definitions used in that environment. ${ }^{25}$

For the U.S. version, the CPT decided to rename the European "Major Competencies" as "Objectives" and the "Supporting Competencies" as "Learning Outcomes," following the Colombian pattern, since we felt that the European terms did not exactly meet the definition of a "competency" in the Preamble of the ADEA Competencies for the New General Dentist: “A 'competency' is a complex behavior or ability essential for the general dentist to begin independent, unsupervised dental practice. Competence includes knowledge, experience, critical thinking and problem-solving skills, professionalism, ethical values, and technical and procedural skills. These components become an integrated whole during the delivery of patient care by the competent general dentist. Competence assumes that all behaviors are performed with a degree of quality consistent with patient well-being and that the general dentist can self-evaluate treatment effectiveness" (p. 813). ${ }^{19}$

Thus, the "Objectives" in the U.S. framework describe the core knowledge, abilities, aptitudes, and attributes that the dental student should achieve for that particular domain. The term "Learning Outcomes" was chosen because those qualities support performance of the main objective. The Learning Outcomes are divided into what the graduate dentist should be "capable of" (as used in the Colombian curriculum; meaning "upon graduation the dentist demonstrates sound theoretical knowledge and understanding of the subject together with an adequate clinical experience to be able to resolve clinical problems independently"), "have knowledge of" ("upon graduation the dentist demonstrates sound theoretical knowledge and understanding of the subject together with limited clinical experience"), and "be familiar with" ("upon graduation the dentist demonstrates a basic understanding of the subject but need not have clinical experience"). Each objective may have one, two, or all three of the possible categories of learning outcomes.

A full-day workshop was held in Boston in March 2015 immediately prior to the 2015 ADEA Annual Session. There were 73 participants in the workshop; participants came from 35 U.S., three Canadian, and four international dental schools (Table 1). The workshop began with presentations from Drs. Nigel Pitts, Andreas Schulte, and Margherita Fontana that provided an overview of the European 
Table 1. Institutions that participated in development of the U.S. cariology curriculum framework

Nova Southeastern University

The University of Texas School of Dentistry at Houston

University of Oklahoma College of Dentistry

University of the Pacific Arthur A. Dugoni School of Dentistry

University of lowa College of Dentistry and Dental Clinics

University of Michigan School of Dentistry

New York University

Stony Brook University School of Dental Medicine

Columbia University College of Dental Medicine

University at Buffalo School of Dental Medicine

University of Maryland School of Dentistry

University of California, San Francisco School of Dentistry

University of Louisville School of Dentistry

Midwestern University College of Dental Medicine-Illinois

Midwestern University College of Dental Medicine-Arizona

University of Kentucky College of Dentistry

Harvard School of Dental Medicine

University of Washington School of Dentistry

Indiana University School of Dentistry

LECOM School of Dental Medicine

Virginia Commonwealth University School of Dentistry

University of Illinois at Chicago College of Dentistry

University of Pittsburgh School of Dental Medicine

Boston University Goldman School of Dental Medicine

University of North Carolina at Chapel Hill School of Dentistry

University of Colorado School of Dental Medicine

Loma Linda University School of Dentistry

University of Florida College of Dentistry

Georgia Regents University College of Dental Medicine

Columbia University

University of Texas Health Science Center at San Antonio School of Dentistry

University of Connecticut School of Dental Medicine

University of California, Los Angeles School of Dentistry

Southern Illinois University School of Dental Medicine

Marquette University School of Dentistry
$X$

$X$

$X$

$X$

$X$

$X$

$X$

$X$

$X$

$X$

$X$

$X$

$\mathrm{X}$

Non-U.S. Institutions

Clark College Dental Hygiene (Canada)

School of Dental Medicine Jerusalem (Israel)

McGill University (Canada)

Université de Montréal (Canada)

University of Dundee (UK)

University of Heidelberg (Germany)

Universidad El Bosque (Colombia)

$\begin{array}{ll}x & \\ x & \\ X & \\ X & x \\ X & x \\ X & x \\ X & \end{array}$

CCC Consensus Workshop, reported on experience in the development and implementation of the curriculum internationally, gave an overview of the present status of U.S. cariology education, ${ }^{26}$ and defined the purpose of the workshop. The CPT randomly divided the 73 participants into five groups, based on each of the five European cariology curriculum domains. For each group of approximately 12 participants, a leadership team (chair and note-taker) was assigned in advance to aid in the process. The domain assignments to the five working groups were as follows: Working Group 1-the knowledge base; Working Group 2 -risk assessment, diagnosis, and synthesis; Working Group 3-treatment decision making: preventive strategies and nonsurgical management; Working Group 4 - treatment decision making: surgical therapy; and Working Group 5-evidence-based cariology in clinical and public practice. 
The tables describing each domain's objectives and learning outcomes were distributed to each group, and the chair and note-takers led the discussion. The main objectives and supportive learning outcomes were accepted, modified, or deleted from the tables and additional ideas included as necessary. A final modified table was presented by each working group to a plenary session. Time for discussion with the other groups was provided to allow further input from all workshop participants. Modified domain tables were distributed to the CPT, chairs, and note-takers at the end of the workshop for their final input and edits.

\section{Phase III: 2015 ADEA Section on Cariology Program}

Following the workshop, the CPT presented the resulting proposed curriculum domains and main objectives at the Section on Cariology program at the 2015 ADEA Annual Session for further discussion and input from a broader audience. This program was cosponsored by the Sections on Operative Dentistry, Community and Preventive Dentistry, and Academic Affairs. A brief introduction to the international implementation of the European CCC was given by Drs. Pitts and Schulte, and the results of the U.S. CCC workshop were presented by Drs. Fontana, Guzmán-Armstrong, and Schenkel, followed by a general discussion.

In the weeks after the ADEA meeting, feedback and comments on the five curricular domains and contents from the workshop and the ADEA program were reviewed, and a first draft of the U.S. document was developed. This draft was then sent to all key representatives (identified by those who had attended either the workshop or the ADEA program or had asked to be identified as such via email) and deans of U.S. dental schools for further review and feedback (Table 1).

\section{Results}

This collaborative effort resulted in a final consolidated document of the domains, main objectives, and supporting learning outcomes for the cariology curriculum framework for U.S. dental education (Appendix). Underlying the framework is a competency statement the group agreed upon and recommends that U.S. dental schools add to their competency documents: "Upon graduation, a dentist must be competent in evidence-based detection, diagnosis, risk assessment, prevention, and nonsurgical and surgical management of dental caries, both at the individual and community levels, and be able to reassess the outcomes of interventions over time."

This competency statement is supported by the curriculum framework comprised of five domains, almost identical to the framework of the European CCC. For each domain, there are main objectives, and each objective has associated and expected learning outcomes. This agreed upon curriculum framework is not meant to be prescriptive, and learning outcomes are by no mean exhaustive, but rather allow for flexibility in each dental school's teaching and assessment structure.

\section{Discussion}

This article describes the process of developing a curriculum framework for teaching cariology in U.S. dental schools and a proposed caries management competency statement. This framework is based on the European and Colombian CCC but reflects the competency framework for U.S. dental education. U.S. dental schools either use the ADEA Competencies for a New General Dentist ${ }^{19}$ or modify the national competencies into a limited number of school-specific competencies. Given this variability, we decided to construct the curriculum framework around a proposed school competency statement, which could then be adapted by each school. This competency statement is associated with objectives and learning outcomes that appear in the curriculum framework, divided into five domains. The nomenclature used (competency, curriculum domain, objective, learning outcome, be capable of, have knowledge of, and be familiar with) was based on that previously used, ${ }^{18,25}$ after adapting it to fit the U.S. educational environment. Furthermore, as this curriculum framework is adapted and implemented by each dental school, there will be a need to map assessment strategies to each of the curriculum components, with assessment methods matching the level of expected learning outcomes. ${ }^{24}$

The process of developing a U.S. cariology curriculum framework was similar to that followed by others ${ }^{18,25}$ in that a preliminary survey of cariology teaching in the U.S. was done ${ }^{26}$ and used to help determine the cariology content included. However, rather than having to start from nothing and requiring a three-day workshop as was done in Europe, ${ }^{18}$ the 
availability of the European CCC as a framework for adoption made it possible to accomplish the goals of the U.S. consensus workshop in a single day.

Current accreditation standards for U.S. dental education emphasize the need for schools to foster critical thinking and prepare graduates to be lifelong learners by helping them learn how to identify and incorporate into practice the best available evidence. ${ }^{13}$ Thus, as with professionalism, these are not specific domains to cariology. However, given their importance to effective caries management, we decided to retain these objectives in the domain "Evidencebased cariology in clinical and public practice" as was done in the European CCC. This focus on learning to think critically and solve problems based on best available evidence also requires a different way of teaching and assessment.

As helpful as it is to have a U.S. curriculum framework, it is equally important to address the multiple factors that will influence its implementation. These factors need to be considered simultaneously with curriculum framework changes in order to facilitate success. Important implementation factors include the following: ${ }^{8}$

1) The need for establishment of a welldefined cariology curriculum that allows the integration of didactic, preclinical, and clinical teaching of all the components needed to support the recommended competency statement on caries management;

2) A dental health record that will support a caries lesion severity and activity classification system, a caries risk assessment protocol, and reassessment plan. Recognition of the dynamic nature of the caries disease and the strategies currently available for non-invasive caries lesion management mandates that the classification of caries lesions be descriptive and specific enough to allow monitoring and assessment if the lesion advances over time. ${ }^{10,27,28}$ Thus, in an era of nonsurgical as well as tooth-preserving surgical treatments, it is necessary to have electronic dental records that can facilitate careful documentation of the location, severity, and activity of carious lesions and changes over time. Regarding caries risk assessment, it is an essential component in the decision making process for the correct prevention and management of dental caries, as well as for establishing appropriate recall intervals. ${ }^{6,29}$ Even when evidence suggests that caries experience is still, unfortunately, the single best predictor for future caries development, ${ }^{29}$ the use of structured forms, although presently having limited validity, should be part of the electronic record. Use of structured caries risk forms aids in the systematic assessment of multiple caries risk factors in practice and objective record-keeping and facilitates patient-centered caries management plans and reassessment over time. ${ }^{4}$ To assist with implementation, caries classification systems and risk forms need to be user-friendly and not time-consuming, facilitate translation of findings into treatment planning modules, aid in quality improvement assessments, and have broad acceptance among students and faculty. Once these forms become part of data-gathering in the patient's personal health record and the information is used in the treatment planning and recall process, dental schools will need to ensure compliance with this process through their quality assurance programs.

3) Need for clinician/faculty training and calibration. Having access to the best evidence is not enough to change the practice model of caries management, but it is a start. ${ }^{8}$ However, maintaining evidence-based knowledge in every aspect of dental practice can be overwhelming; the volume of information is substantial and frequently difficult to locate, and it may be difficult to separate appropriate science from unreliable information. Thus, dental schools have very important roles in facilitating access to cariology curricular content for clinical and part-time faculty members and in helping clinicians make sense of available evidence. Lack of training and calibration can have devastating effects on any clinical or educational cariology program,,$^{30,31}$ especially when the program is trying to teach clinicians to manage a disease whose diagnosis and management paradigms have undergone the large shifts that have occurred in cariology. Furthermore, systematic reviews suggest that mere passive dissemination of information is generally ineffective in bringing about change: this information includes educational materials (recommendations for clinical care, including clinical practice guidelines, audiovisual materials, and electronic publications) and attending didactic educational meetings. ${ }^{32}$ Therefore, active training programs have to be developed (and resources planned and allocated) to educate practitioners in various aspects of modern caries management, including case discussions and hands-on training activities.

4) Outcomes assessment (productivity). Assessment and reimbursement of services, or the lack thereof, are often said to be barriers to the rapid 
implementation of advances in dentistry into practice; in fact, if no value is given to procedures or treatment philosophies, they will likely not be adopted. ${ }^{8}$ Thus, solutions must be considered to adequately reimburse the clinical time spent performing diagnosis and nonsurgical management of dental caries comparable to reimbursement for surgical time. Implementation of school-based diagnostic codes and risk-based codes can facilitate tracking and assessment of behaviors to be enhanced. In addition, assessment of how well a student is progressing towards meeting the proposed caries management competency statement is an essential component of the implementation strategy.

5) Effective communication between faculty with responsibilities for the educational processes (determination and delivery of specific content and assessment) for each of the five curriculum domains, including surgical and nonsurgical caries management, is an integral aspect of successful implementation of the framework. Survey data suggest these responsibilities are normally housed in a variety of departments such as restorative dentistry, operative dentistry, preventive dentistry, cariology, and pediatric dentistry. ${ }^{26}$ Thus, implementation and assessment of the framework may need to cross departments in order to be successful.

\section{Conclusion}

This article has described the consensus process used to develop a competency-based U.S. cariology curriculum framework, which can serve as a resource and benchmark for improving the teaching of cariology in U.S. dental schools. As schools assess their cariology education, they should also consider and assess the multiple factors that will influence its implementation, including the need for establishment of a well-defined cariology curriculum; availability of a caries classification system in the electronic health record that allows assessment of caries disease severity and activity, as well as risk assessment, for active monitoring of risk-based caries management strategies and appropriate care at regular intervals over time; evaluating and maintaining evidence-based knowledge in cariology for their faculty members through training and calibration activities, in many cases across multiple departments; and developing reward models to support risk-based nonsurgical caries management activities throughout the didactic and clinical portions of schools' curricula.

\section{Acknowledgments}

The authors are grateful for the assistance and contribution of all workshop participants and representatives of U.S. dental schools who commented on this framework.

\section{REFERENCES}

1. Longbottom C, Huysmans MC, Pitts N, Fontana M. Glossary of key terms. Mongr Oral Sci 2009;2:209-16.

2. Fontana M, Young D, Wolff M, et al. Defining dental caries for 2010 and beyond. Dent Clin North Am 2010;54: 423-40.

3. Kassebaum NJ, Bernabe E, Dahiya M, et al. Global burden of untreated caries: a systematic review and metaregression. J Dent Res 2015;94(1):1-9.

4. Fontana M. The clinical, environmental, and behavioral factors that foster early childhood caries. Pediatr Dent, forthcoming.

5. Zero D, Fontana M, Lennon AM. Clinical applications and outcomes of using indicators of risk in caries management. J Dent Educ 2001;65(10):1126-32.

6. Featherstone JDB. The science and practice of caries prevention. J Am Dent Assoc 2000;131:887-99.

7. Featherstone JDB. The caries balance: contributing factors and early detection. J Calif Dent Assoc 2003;31(2): 129-33.

8. Fontana M, Wolff M. Opportunities and challenges for caries management. J Calif Dent Assoc 2011;39(10): $702-8$.

9. Yorty JS, Walls AT, Wearden S. Caries risk assessment/ treatment programs in U.S. dental schools: an eleven-year follow-up. J Dent Educ 2011;75(1):62-7.

10. Pitts NB, Ekstrand KR, ICDAS Foundation. International caries detection and assessment system (ICDAS) and its international caries classification and management system (ICCMS): methods for staging of the caries process and enabling dentists to manage caries. Community Dent Oral Epidemiol 2013;41(1):41-52.

11. Fontana M, Zero D. Bridging the gap in caries management between research and practice through education: the Indiana University experience. J Dent Educ 2007;71(5):579-91.

12. Chaffee BW, Featherstone JD. Long-term adoption of caries management by risk assessment among dental students in a university clinic. J Dent Educ 2015;79(5):539-47.

13. Commission on Dental Accreditation. Accreditation standards for dental education programs. 2013. At: www ada.org/ /media/CODA/Files/predoc.ashx. Accessed 11 May 2015.

14. Riley JL 3rd, Gordan VV, Ajmo CT, et al. Dentists' use of caries risk assessment and individualized preventive for their adult patients: findings for the dental practicebased research network. Community Dent Oral Epidemiol 2011;39:564-73.

15. Schulte AG, Buchalla W, Huysmans MC, et al. A survey on education in cariology for undergraduate dental students in Europe. Eur J Dent Educ 2011;15(1):3-8.

16. Martignon S, Gomez J, Tellez M, et al. Current cariology education in dental schools in Spanish-speaking Latin American countries. J Dent Educ 2013;77(12):1330-7. 
17. Ferreira-Nóbilo NP, de Sousa MLR, Cury JA. Cariology in curriculum of Brazilian dental schools. Braz Dent J 2014;25(4):265-70.

18. Schulte AG, Pitts NB, Huysmans MC, et al. European core curriculum in cariology for undergraduate dental students. Eur J Dent Educ 2011;15(1):9-17.

19. American Dental Education Association. ADEA competencies for the new general dentist. J Dent Educ 2015;79(7):813-6.

20. Anderson P, Beeley J, Monteiro PM, et al. A European core curriculum in cariology: the knowledge base. Eur J Dent Educ 2011;15(1):18-22.

21. Pitts N, Melo P, Martignon S, et al. Caries risk assessment, diagnosis, and synthesis in the context of a European core curriculum in cariology. Eur J Dent Educ 2011;15(1): 23-31.

22. Bottenberg P, Ricketts DN, Van Loveren C, et al. Decision making and preventive nonsurgical therapy in the context of a European core curriculum in cariology. Eur J Dent Educ 2011;15(1):32-9.

23. Buchalla W, Wiegand A, Hall A. Decision making and treatment with respect to surgical intervention in the context of a European core curriculum in cariology. Eur J Dent Educ 2011;15(1):40-4.

24. Splieth CH, Innes N, Söhnel A. Evidence-based cariology in clinical and public health practice as part of the European core curriculum in cariology. Eur J Dent Educ 2011;15(1):45-51.
25. Martignon S, Marin LM, Pitts N, et al. Consensus on domains, formation objectives, and contents in cariology for undergraduate dental students in Colombia. Eur J Dent Educ 2014;18:1-12.

26. Fontana M, Horlak D, Sharples S, et al. Teaching of cariology in U.S. dental schools. J Dent Res 2012;91(Spec Iss A):Abstract 313 .

27. Young DA, Novy BB, Zeller GG, et al. The American Dental Association caries classification system for clinical practice: a report of the American Dental Association Council on Scientific Affairs. J Am Dent Assoc 2015;146(2):79-86.

28. Ismail AI, Tellez M, Pitts NB, et al. Caries management pathways preserve dental tissues and promote oral health. Community Dent Oral Epidemiol 2013;41(1):12-40.

29. Twetman S, Fontana M, Featherstone J. Risk assessment: can we reach consensus? Community Dent Oral Epidemiol 2013;41(1):64-70.

30. Teich ST, Demko C, Al-Rawi W, et al. Assessment of implementation of a CAMBRA-based program in a dental school environment. J Dent Educ 2013;77(4):438-47.

31. Rechmann P, Featherstone JD. Quality assurance study of caries risk assessment performance by clinical faculty members in a school of dentistry. J Dent Educ 2014;78(9):1331-8.

32. Bero LA, Grilli R, Grimshaw JM, et al. Closing the gap between research and practice: an overview of systematic reviews of interventions to promote the implementation of research findings. BMJ 1998;317(7156):465. 


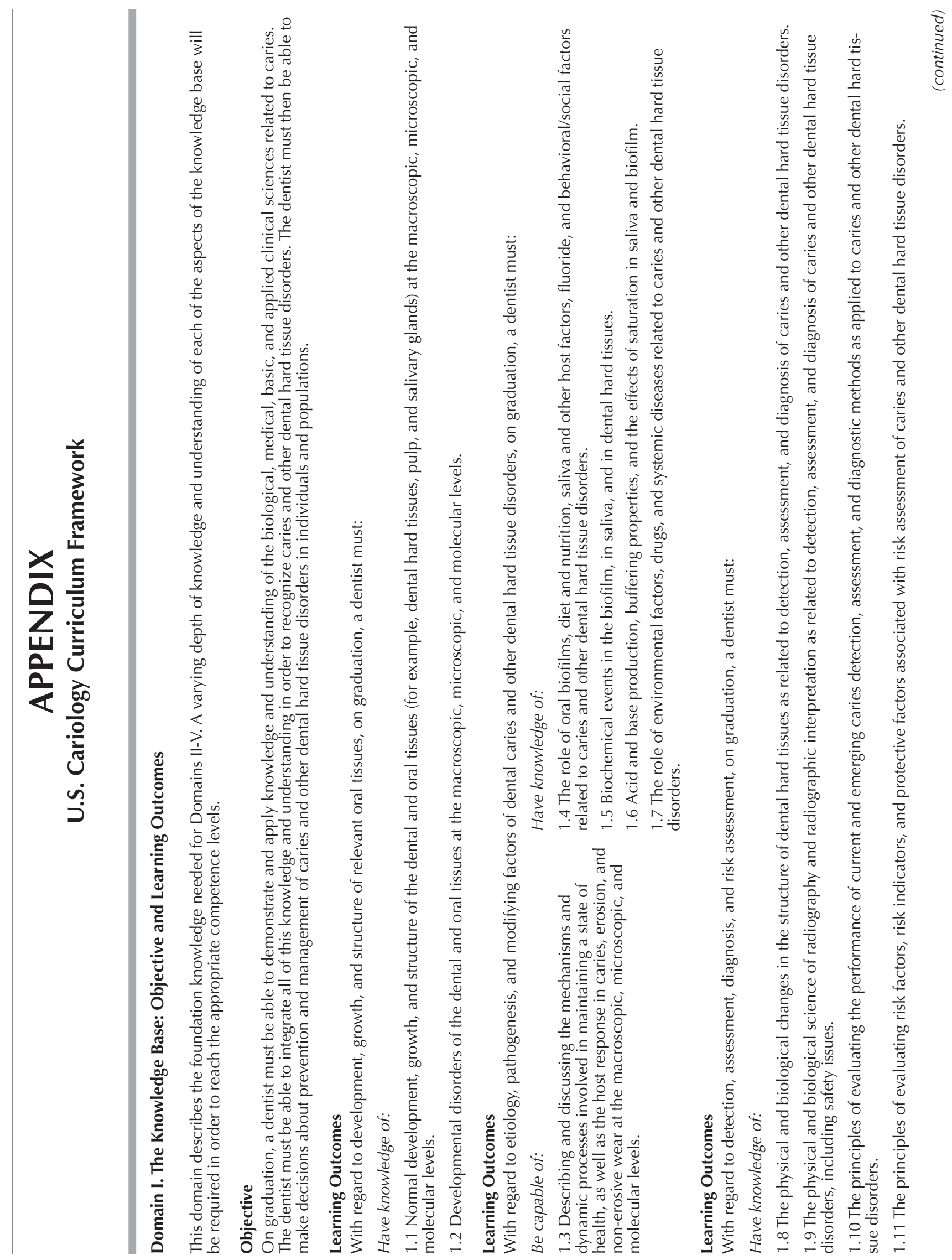




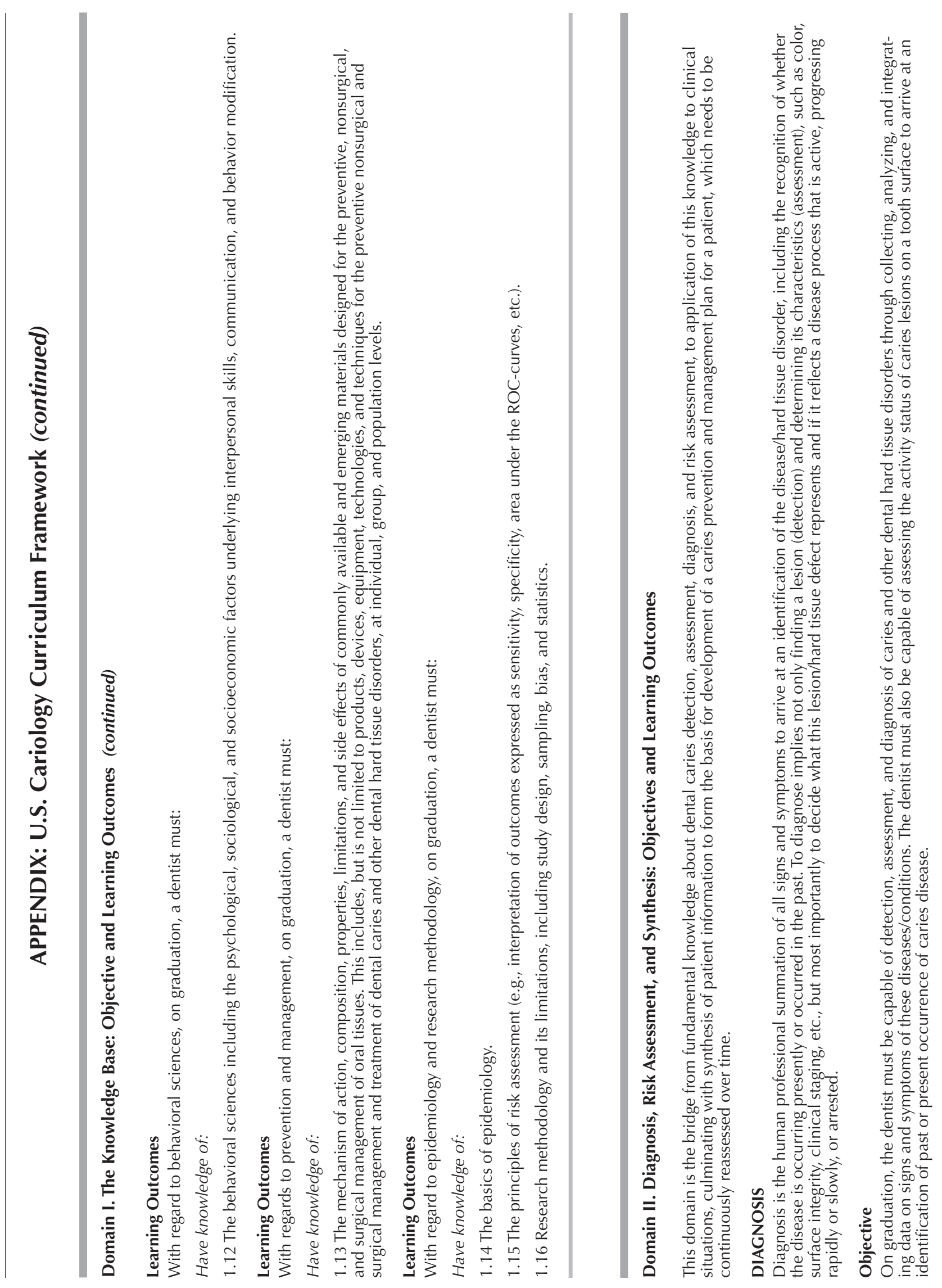




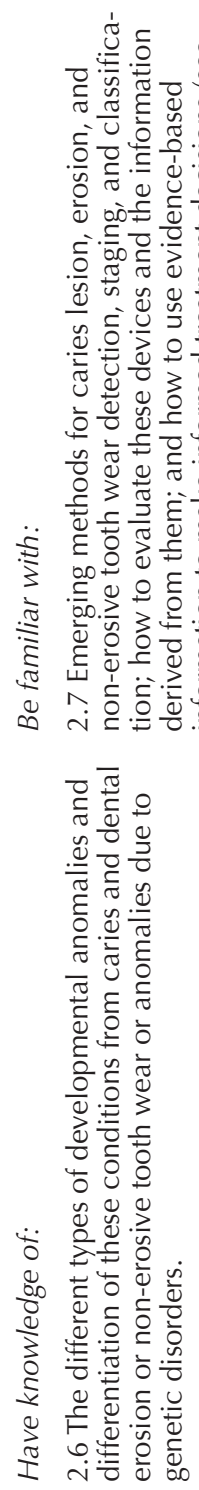

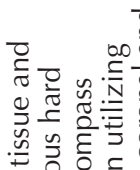

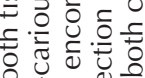

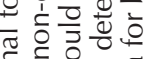

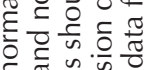

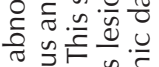

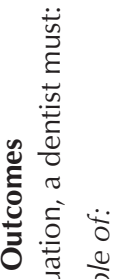

돈

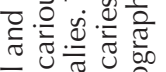

ฮั

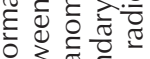

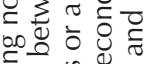

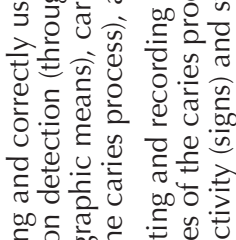

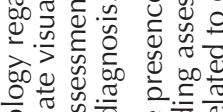

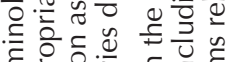

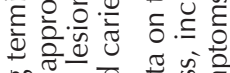

든.

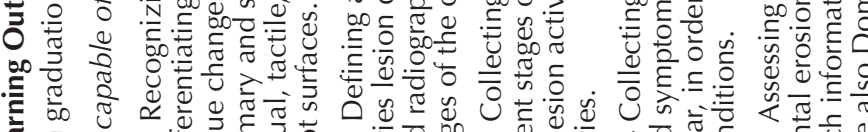

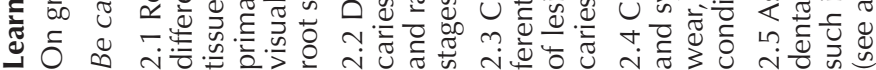

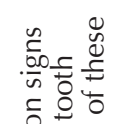

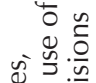

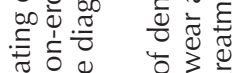

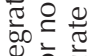

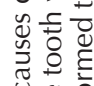

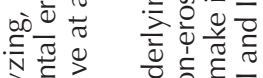

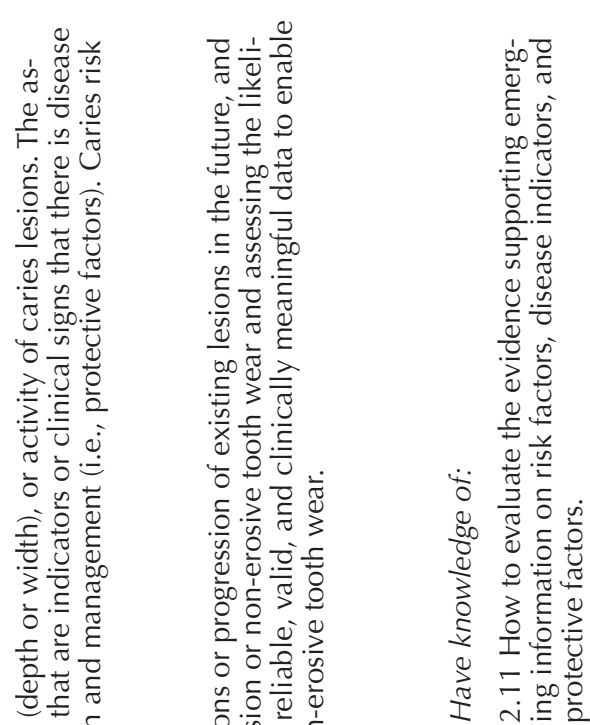

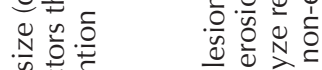

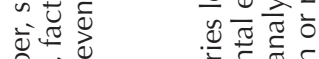

है के

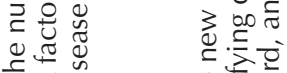

㲅

80

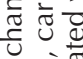

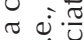

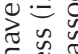

उ흥

业

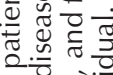

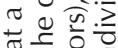

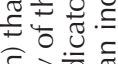

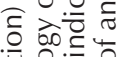

응

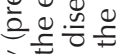

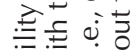

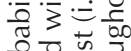

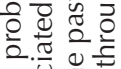

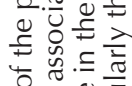

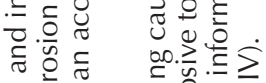

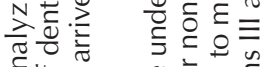

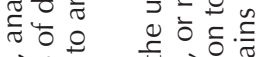

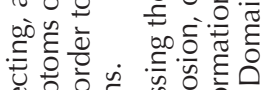

w

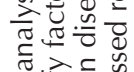

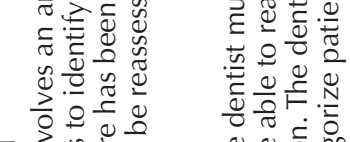

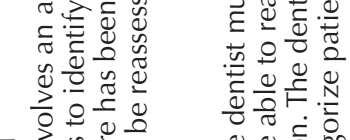

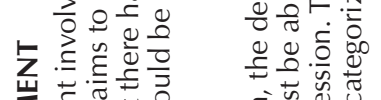

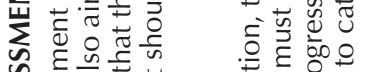

岁

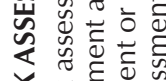

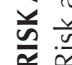

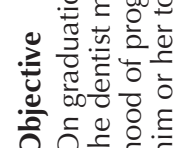

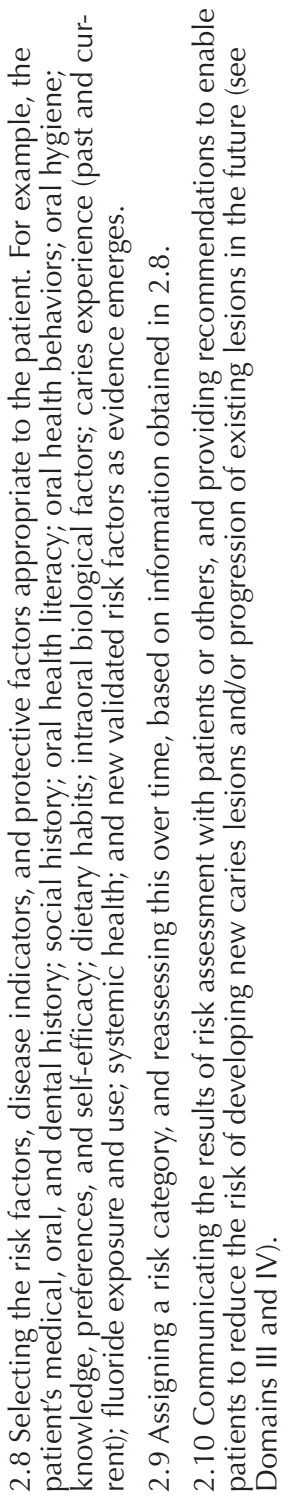




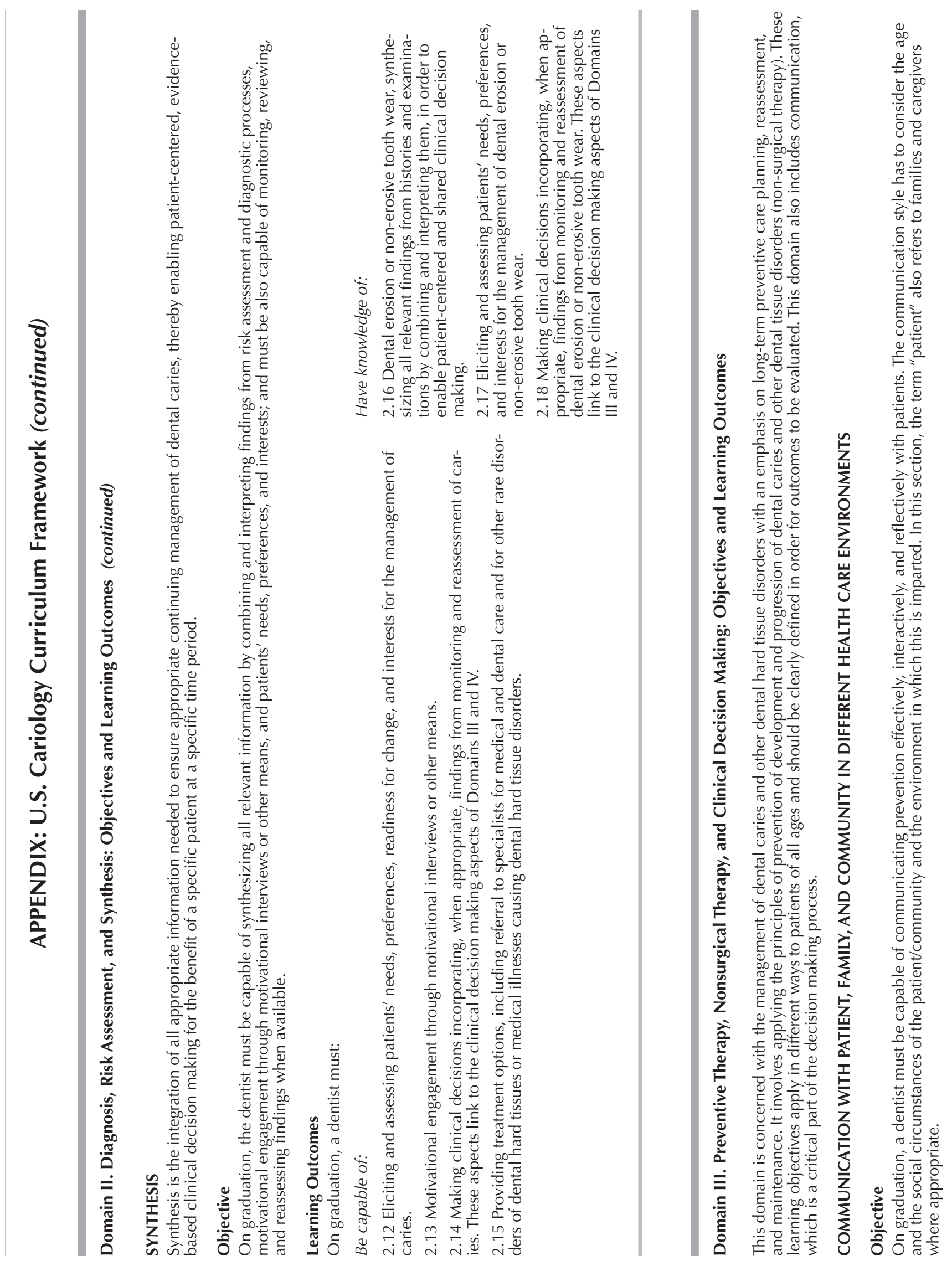




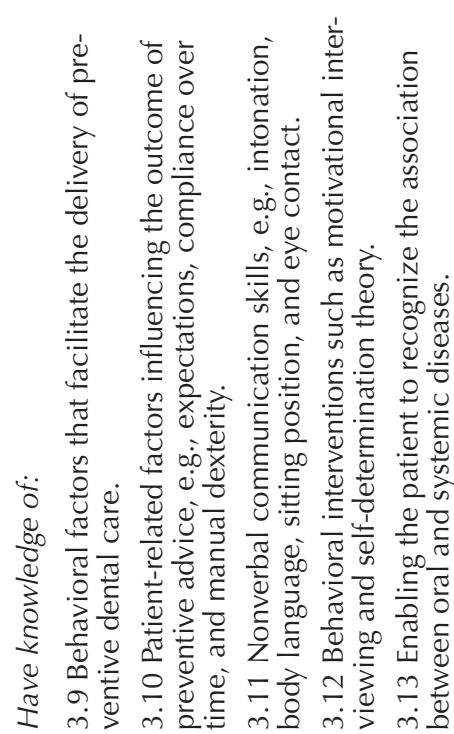

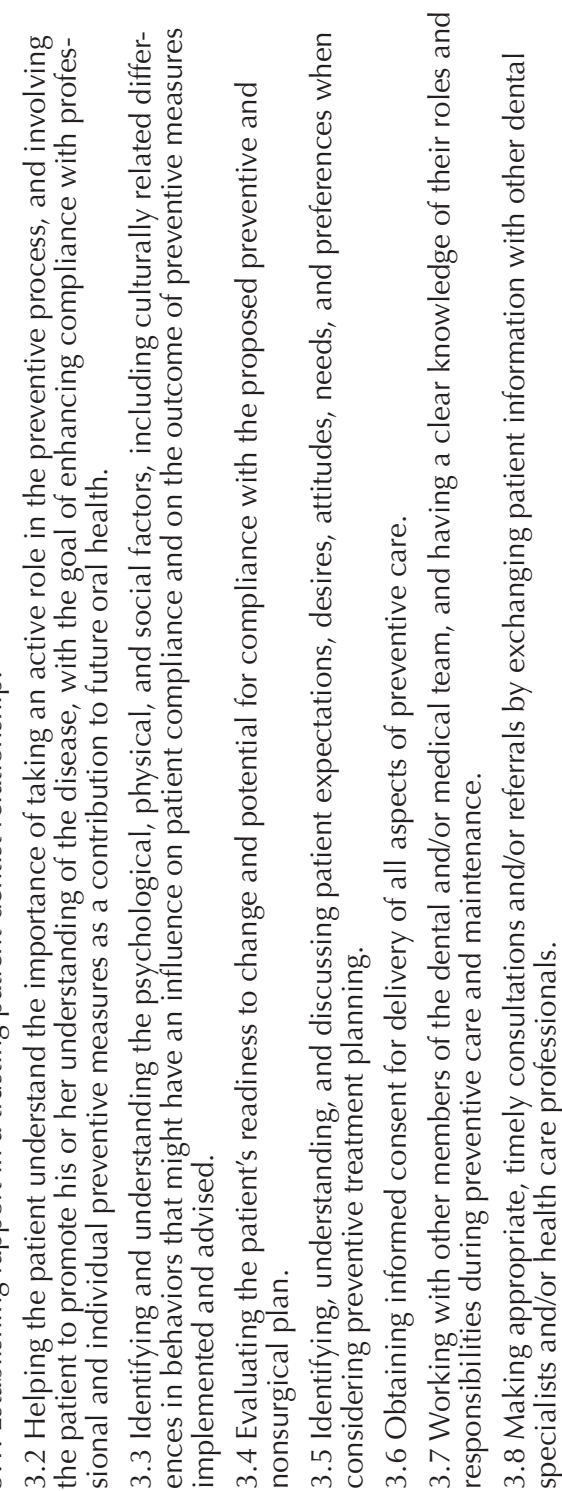

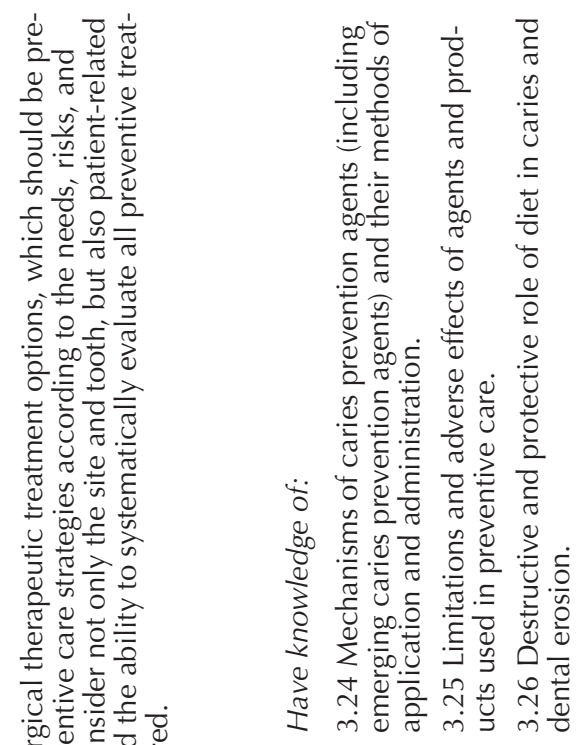

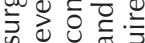

동 흔 월

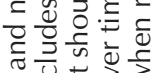

ฮั

.

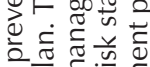

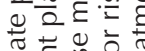

خ

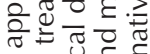

호앙

$\frac{\pi}{5} . \underline{N} \sum^{0} \tilde{d}$

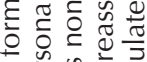

원 $\frac{\omega}{2}$

音

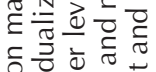

:

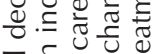

정ํํ

ฮั

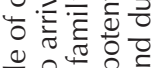

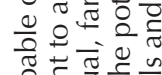

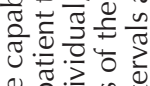

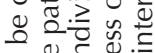

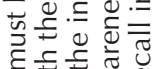

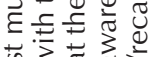

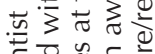

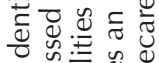

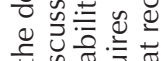

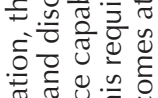

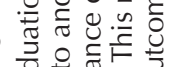

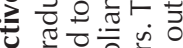

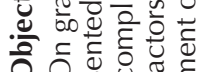

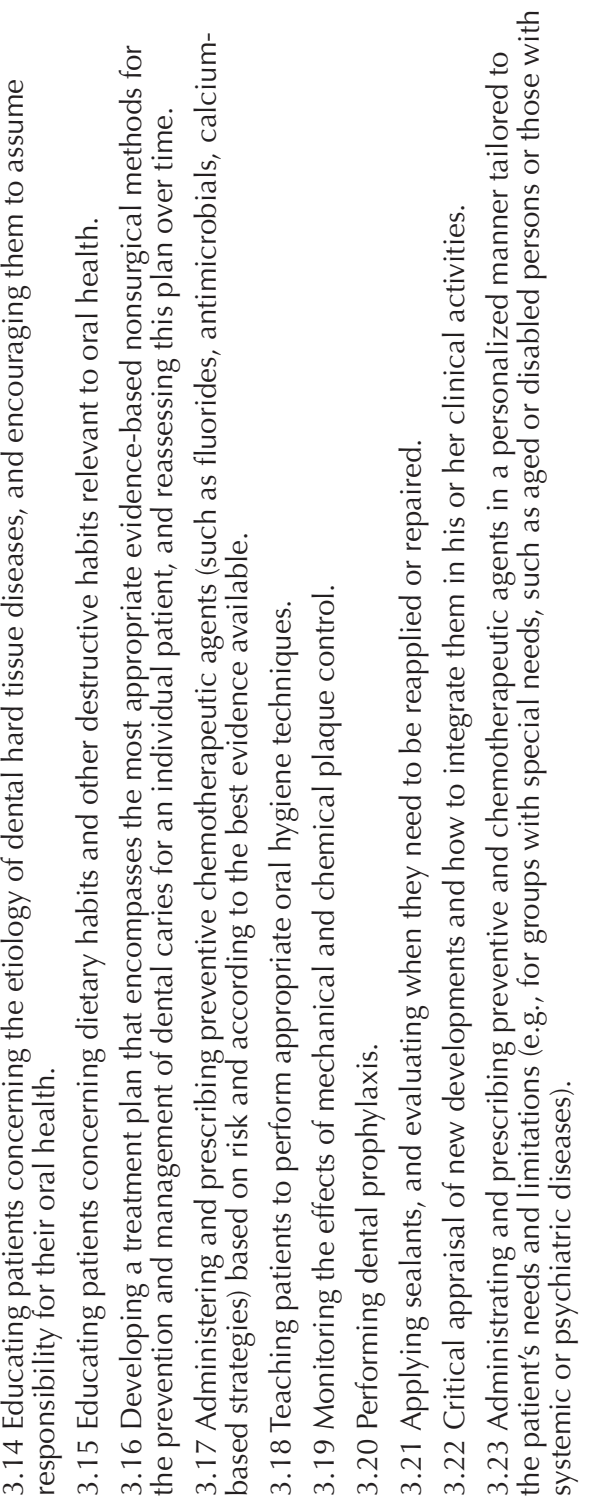




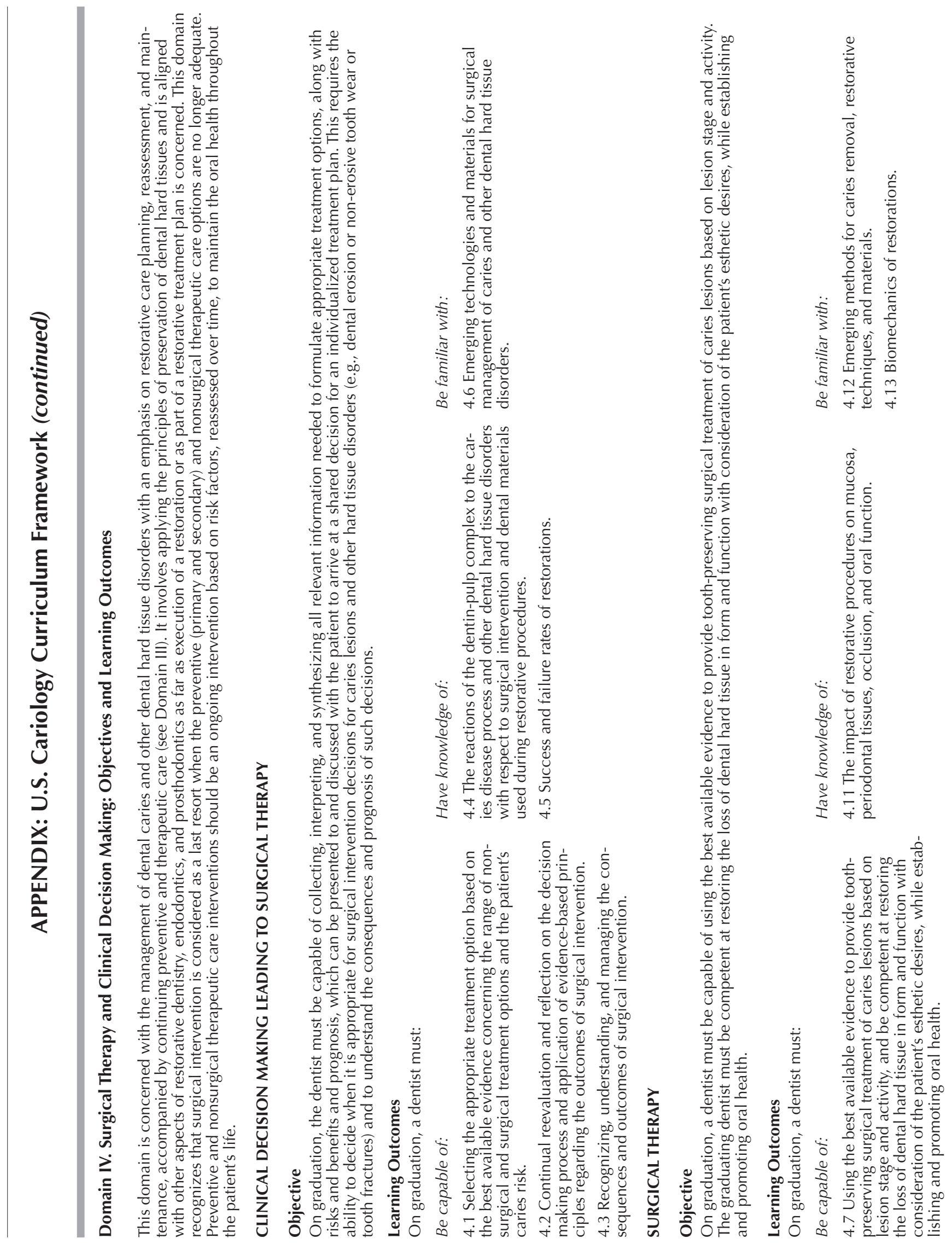




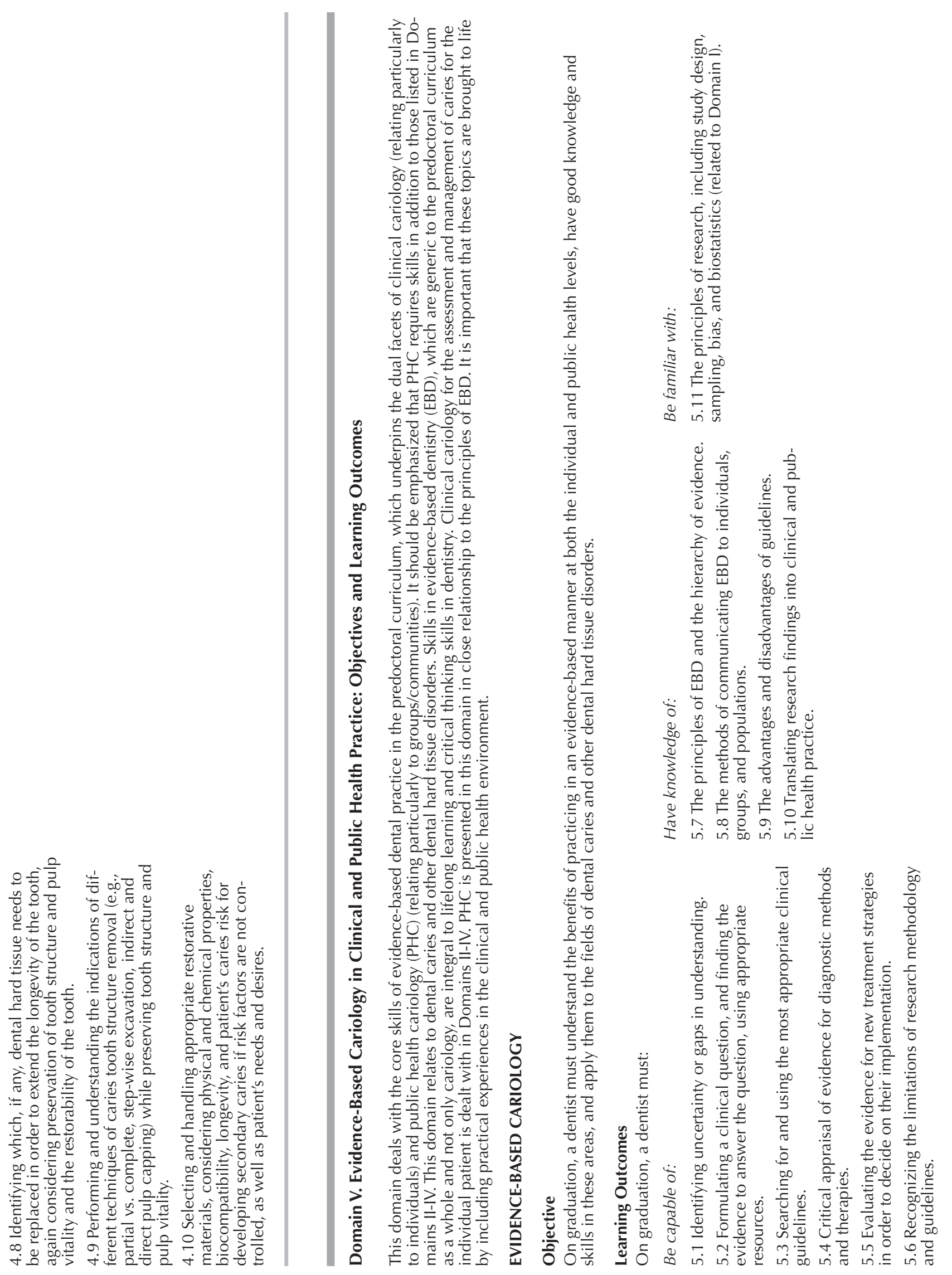




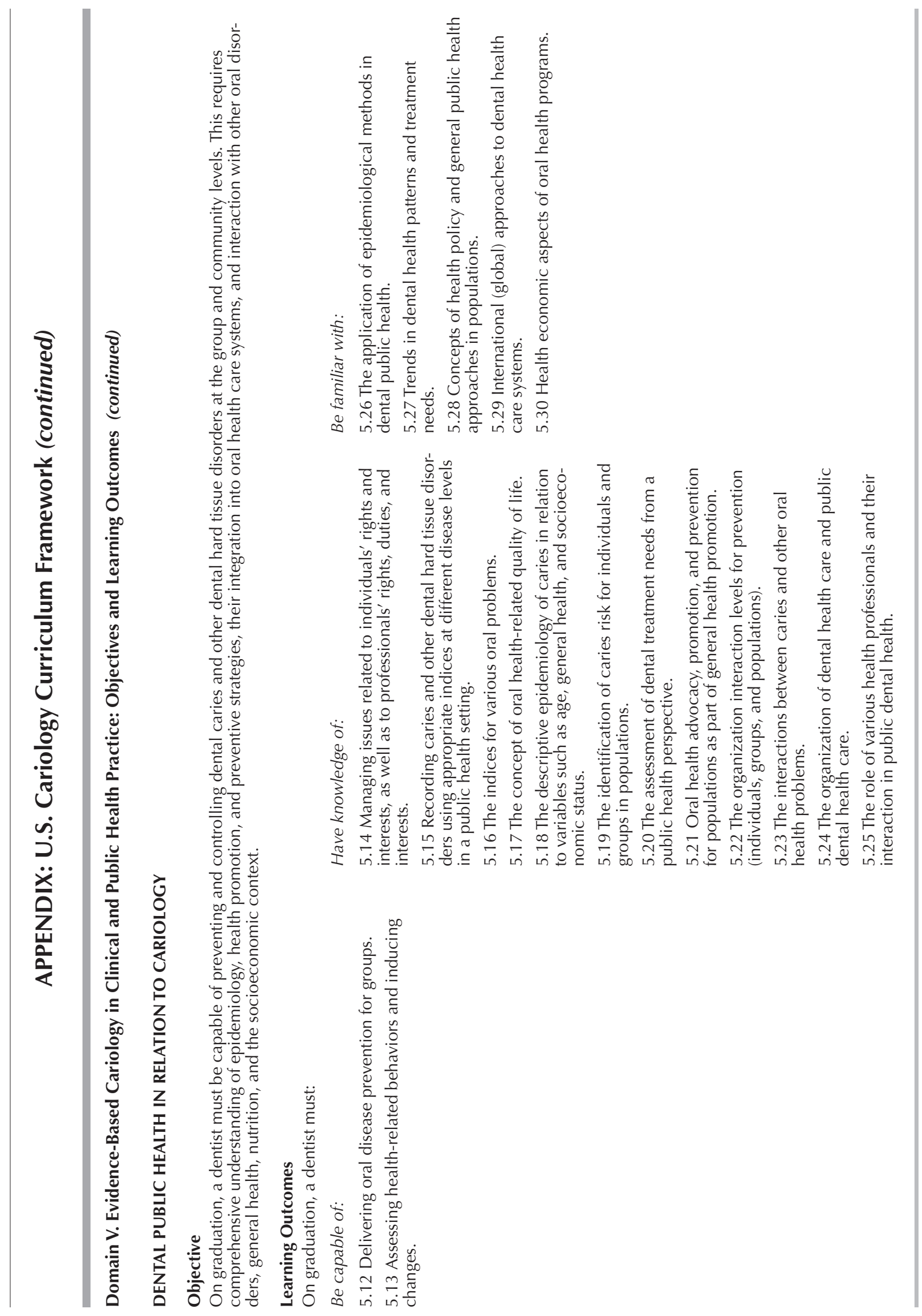

